\title{
Towards a Molecular Interpretation of Astringency: Synthesis, 3D Structure, Colloidal State, and Human Saliva Protein Recognition of Procyanidins
}

Authors

Affiliations
Olivier Cala ${ }^{2}$, Sandy Fabre ${ }^{1}$, Noël Pinaud ${ }^{1}$, Erick J. Dufourc ${ }^{2}$, Eric Fouquet ${ }^{1}$, Michel Laguerre ${ }^{2}$, Isabelle Pianet ${ }^{1}$

${ }^{1}$ UMR 5255 ISM CESAMO, Université Bordeaux, CNRS, Talence, France

2 UMR 5248 CBMN, Université Bordeaux, CNRS, ENITAB, IECB, Pessac, France
Key words

procyanidin

proline rich peptide

astringency

- NMR

- molecular dynamics received October 6, 2010 revised February 4, 2011 accepted February 8, 2011

\section{Bibliography}

DoI http://dx.doi.org/

10.1055/s-0030-1270848

Published online March 16,

2011

Planta Med 2011; 77:

1116-1122 @ Georg Thieme Verlag KG Stuttgart - New York · ISSN 0032-0943

\section{Correspondence}

\section{Dr. Isabelle Pianet}

Institut des Sciences

Moléculaires, CESAMO

Université Bordeaux 1

351 Cours de la Libération

33405 Talence

France

Phone: + 33540006448

Fax: + 33540002623

i.pianet@ism.u-bordeaux1.fr

\section{Abstract}

$\nabla$

Astringency is a sensation in the mouth used in judging the quality of red wine. The rough, dry, and puckering sensation called astringency is the result of an interaction between tannins and saliva proteins, mainly proline-rich proteins (PRP), which leads to the formation and precipitation of a complex. A dry and rough sensation is then perceived in the mouth. To get an insight into astringency at the molecular level we investigated: (i) An efficient and iterative method for 4-8 procyanidin synthesis, which gives rise to all possible 48 procyanidins up to the tetramer with total control of degree of oligomerization and stereochem-

\section{Introduction}

$\nabla$

Astringency is not a taste but a tactile sensation felt in the entire mouth [1]. This feeling is the result of a strong interaction between tannins and saliva proteins leading to the formation of a supramolecular colloidal complex that can precipitate and, consequently, modify the palate lubrication [2]. Numerous specific terms have been used to describe the intricate sensation of astringency of alcoholic beverages [3], especially red wine, this vocabulary being associated to either gustative qualities or defaults. One possible way to explain the complex oral perceptual phenomenon induced by tannins might be their high level of structural polymorphism [4]. Wine tannins are mainly derived from the solid part of the grape and are transferred to wine during the maceration process. The major tannins present in wine come from the proanthocyanidin family, especially procyanidins. They are polymers of 2 basic units that can be distinguished from each other by the stereochemistry on carbon 3 ( Fig. 1 ). The polymerization process takes place from the C4 of an upper unit and the C6 or C8 of a lower istry. (ii) The 3D-structural preferences, which take into account their internal movements, using 2D NMR and molecular modeling. (iii) The self-association process in water or hydroalcoholic solutions using diffusion NMR spectroscopy that gives the active proportion of tannins able to fix proteins. (iv) A comprehensive description of the PRP-procyanidin complex formation to get information about stoichiometry, binding site localization, and affinity constants for different procyanidins. The data collected suggest that the interactions are controlled by both procyanidin conformational and colloidal state preferences. All these results provide new insights into the molecular interpretation of tannin astringency.

unit, leading to potentially 8 different dimers, 32 trimers, 128 tetramers, and so on. It is commonly acknowledged that the concentration of tannin in wine influences wine taste and is dependent on factors including soil, vintage, wine-making process, vine, or weather [5]. However, little is known about the influence of procyanidin structure and colloidal state on astringency.

In the present work, we try to decipher some facets of astringency by adopting the following strategy. First, a new way to synthesize procyanidins by controlling both the stereo- and regiochemistry of the interflavan link as well as their polymerization degree was developed [6]. Second, structural preferences $[7,8]$ and colloidal state of defined procyanidins [9] were investigated in a wine-like medium using NMR and molecular modeling. And third, the interaction of different procyanidins with a peptide representative of a human saliva proline-rich protein (PRP, $\bullet$ Fig. 2) was investigated. This protein plays a key role in astringency owing to its strong affinity for polyphenols [10]. This study, using NMR and molecular dynamics [11], sheds new light on the understanding of astringency at a molecular level. 
<smiles>Oc1cc(O)c2c(c1)O[C@H](c1ccc(O)c(O)c1)[C@H](O)[C@H]2O</smiles>

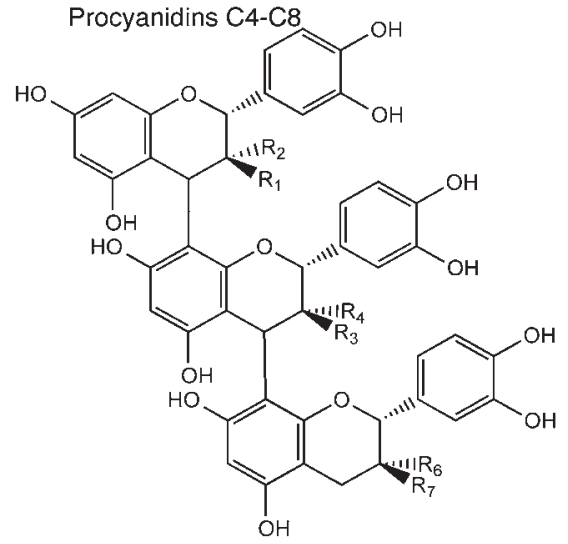<smiles>CCOCCOCCOc1cc(O)cc(O)c1C</smiles>

Nomenclature

dimers $(n=0)$

$\mathrm{B} 1: \mathrm{R} 1=\mathrm{R} 4=\mathrm{H} ; \mathrm{R} 2=\mathrm{R} 3=\mathrm{OH} ;-=$

$\mathrm{B} 2: \mathrm{R} 1=\mathrm{R} 3=\mathrm{H} ; \mathrm{R} 2=\mathrm{R} 4=\mathrm{OH} ;-=-$

B3: $\mathrm{R} 2=\mathrm{R} 4=\mathrm{H} ; \mathrm{R} 1=\mathrm{R} 3=\mathrm{OH} ;-=\ldots \mathrm{m}+\mathrm{I}$

$\mathrm{B} 4: \mathrm{R} 2=\mathrm{R} 3=\mathrm{H} ; \mathrm{R} 1=\mathrm{R} 4=\mathrm{OH} ;-=\ldots+\cdots+1$

trimer $(n=1)$

$\mathrm{C} 2$ : R2=R4=R6 =H ; R1=R3=R7=OH ; $-=\ldots+\ldots 11$
Fig. 1 Procyanidin structures. The two monomers catechin and epicatechin (upper) and C4-C8 procyanidin polymers (bottom).
1B7: SPPGKPOGPPPQGGNQPQGPPPPGKPOGPPPQGGNKPQGPPPPGKPOGPPPQGDNKSR ${ }^{59}$

$1 \mathrm{~B} 8 \mathrm{c}:$ SPPGKPQGPP$P Q G \mathrm{NQPQGPPPPPGKPQGPPPQGGNKPQGPPPPGKPQGPP}$ PQGGSKSRSA ${ }^{61}$ IB9 : SPPGKPOGPPPQGGNQPQGPPPPPGKPQGPPPQGGNKPQGPPPPGKPOGPPPQGDKSRSPR ${ }^{61}$ IB7-14: SPPGKPOGPPPQGG $^{14}$
Fig. 2 PRP structures showing their common repeated region.

\section{Materials and Methods}

\section{Procyanidin synthesis}

Procyanidins dimers and trimers were synthesized using a general way to obtain procyanidins, in quantity, regio- and stereocontrolled at the level of the interflavan bond [6].

IB7-14, a 14 residues peptide representative of human saliva PRPs, was synthesized using a solid phase Fmoc synthesis strategy as previously described [12].

\section{NMR experiments}

NMR was used for the following purposes:

(i) To determine the 3D structure of tannin or peptide alone or for the tannin/peptide complex: in this case, we used the classical 1D- 2D NMR experiments such as COSY, TOCSY, NOESY, HSQC, and $\mathrm{HMBC}$.

(ii) To measure physicochemical parameters governing the selfassociation of tannins. To do so diffusion coefficients (D) variations were followed at various concentrations of tannins. D was obtained from DOSY NMR as previously described [13]. The change in $\mathrm{D}$ with respect to tannin concentrations was fit to the relationship shown below to obtain the association constant value Ka [14]:

$$
\Delta \mathrm{D}=\left|\mathrm{D}_{\text {obs }}-\mathrm{D}_{\text {free }}\right|=\left(\mathrm{D}_{\max }-\mathrm{D}_{\text {free }}\right) \mathrm{Ka}\left[\mathrm{T}_{0}\right]\left\{2 /\left[1+\left(\left\{\mathrm{Ka}\left[\mathrm{T}_{0}\right]+1\right)^{1 / 2}\right]\right\}^{1}\right.
$$

$D_{\text {obs }}$ is the observed D; $D_{\text {free }}$ is the $D$ of the non-associate tannin; $D_{\text {max }}$ is the maximal $\mathrm{D}$ of the tannin $\mathrm{T}$ present in an aggregated form; and $\left[\mathrm{T}_{0}\right]$ is the total concentration of tannins. The CMC value (critical micelle concentration) of the tannins could also be deduced: when $\mathrm{D}$ values were plotted against the inverse of the concentration, two straight lines with different slopes were obtained, and the $\mathrm{x}$-coordinate of the intersection point between the two straight lines gave the CMC values.

(iii) To measure physicochemical parameters characterizing the interaction between the peptide and the tannins [11]. Notably, the stoichiometry and the dissociation constant of the complex were obtained by fitting the chemical shift variations of characteristic protons of the peptide at different tannin/peptide ratios using Equation 2 [15]:

$\Delta \delta=1 / 2 \Delta \delta_{\max } \quad\left[\left(1+\mathrm{Kd} / \mathrm{n}\left[\mathrm{P}_{0}\right]+[\mathrm{Ti}] / \mathrm{n}\left[\mathrm{P}_{0}\right]\right)-\left\{\left(1+\mathrm{Kd} / \mathrm{n}\left[\mathrm{P}_{0}\right]+[\mathrm{Ti}] / \mathrm{n}\right.\right.\right.$ $\left.\left.\left.\left[\mathrm{P}_{0}\right]\right)^{2}-4[\mathrm{Ti}] / \mathrm{n}\left[\mathrm{P}_{0}\right]\right]^{1 / 2}\right]$

$\mathrm{Kd}$ is the dissociation constant of the tannin peptide complex; $\mathrm{n}$ is the number of tannins able to bind to the peptide; [Ti] is the tannin concentration able to bind the peptide; and $\left[\mathrm{P}_{0}\right]$ is the peptide concentration. Following the size of the complex through diffusion measurement by DOSY NMR gives rise to the same parameters. In this case, equation 2 was used but with $\mathrm{D}$ instead of $\Delta \delta$. 


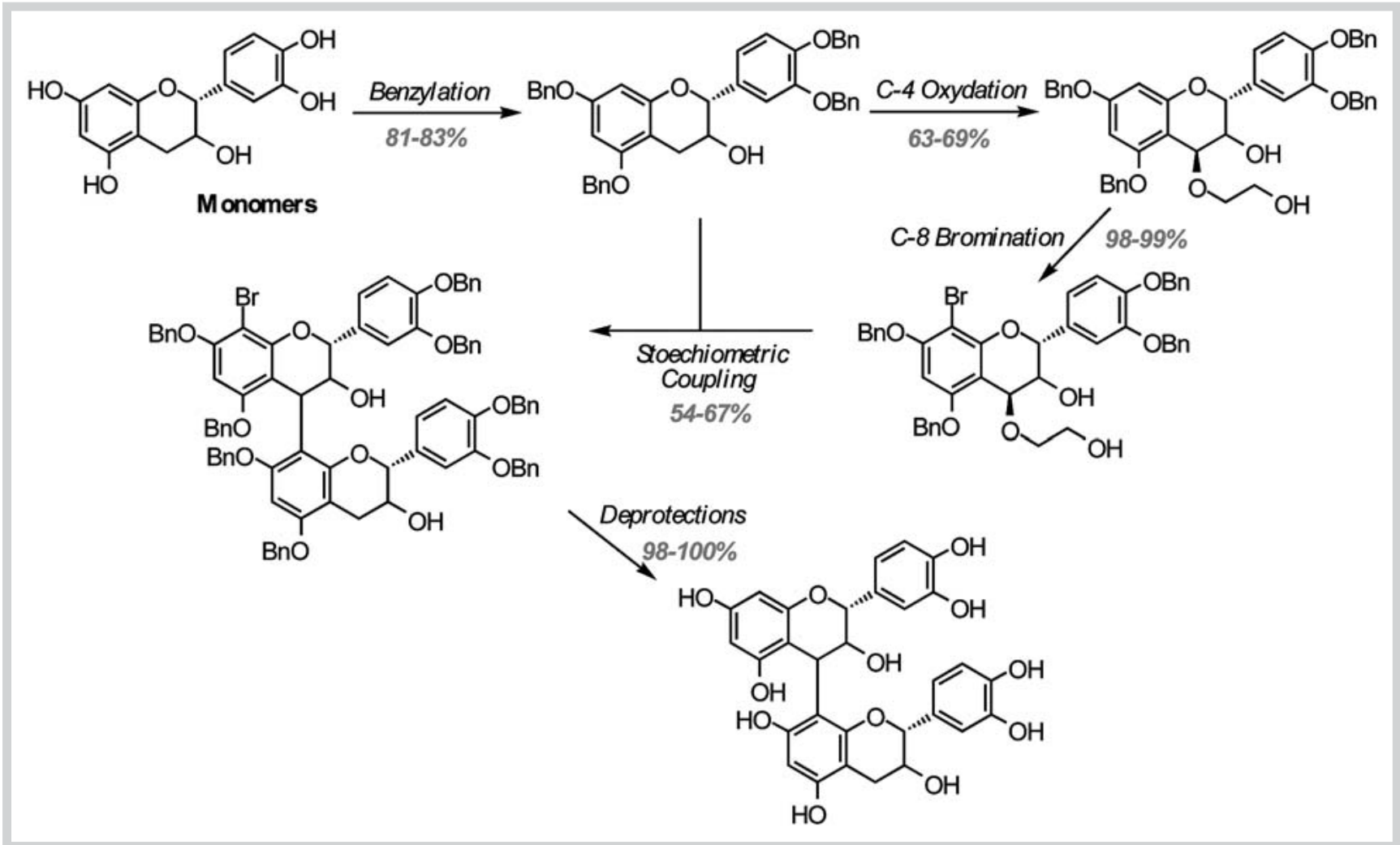

Fig. 3 General strategy to synthesize procyanidin 4-8 dimers.

\section{Molecular modeling}

Molecular modeling and dynamic calculations were performed on a SGI Octane R10 K work station using different force fields depending on the systems considered: MM3 was used for all 3D structure determination of tannins $[7,8]$ whereas the AMBER force field was used to obtain the $3 \mathrm{D}$ structure of the peptide IB7-14 or the IB7-14/B3 complex [11].

\section{Results and Discussion}

$\nabla$

The general approach for synthesis of 4-8 linked procyanidins was based on the stoichiometric coupling of 2 tetrabenzylated monomeric units with a $\mathrm{TiCl}_{4}$ catalyst: the nucleophilic partner was the tetrabenzylated monomer and the electrophilic partner was the C4-activated and C8-protected tetrabenzylated monomer ( Fig. 3). This strategy was inspired by two different works: Tückmantell and coworkers, who developed the coupling strategy between nucleophilic and electrophilic partners [16] and Saito and coworkers who protected the $\mathrm{C} 8$ of the electrophilic partner to control the degree of polymerization [17]. Using this general strategy, we produced all the 4-8 procyanidin dimers with relatively good overall yields: $29 \%$ for $\mathrm{B} 1,27 \%$ for $\mathrm{B} 2,38 \%$ for B3, and $30 \%$ for $\mathrm{B} 4$.

The synthesis of all the 8 (4-8) trimers was also possible by using the same strategy. Two ways are possible ( $\bullet$ Fig. 4):

Method 1: The compound resulting from the coupling step (the benzylated and C8-brominated dimer) could be used as the nucleophilic partner after C-8 debromination, while the activated monomer was used as the electrophilic partner. In this case, an upper extension occurred with a total overall yield of $27 \%$.
Method 2: The octobenzylated C8-protected dimer could be C4oxidized to form the electrophilic partner followed by coupling to the tetrabenzylated monomer to form a trimer. In this case a lower extension occurred with a total overall yield of $18 \%$.

Procyanidins occur in a conformational mixture in solution owing to two distinct conformational mechanisms:

(i) The heterocyclic ring (C, F, I) oscillates between two states where the 2-aryl group is in a pseudo-equatorial (Eq) or -axial (Ax) position. This phenomenon is extremely rapid with regard to the NMR time scale so that the measurement of ${ }^{1} \mathrm{H}$ coupling constants between the $\mathrm{H} 2$ and the $\mathrm{H} 3$ of each heterocyclic ring gives rise to the $(\mathrm{Eq}) /(\mathrm{Ax})$ ratio [18].

(ii) The interflavanoid bond decreases the rotational rate due to steric hindrance. Two rotameric forms (compact and extended) are expected at each interflavanoid link [19].

(iii) The systematic study of the four 4-8 procyanidin dimers and the trimer $\mathrm{C} 2$ in water or in a wine-like medium shows that these two mechanisms are responsible for the 3D-structural differences. These differences are not really predictable from one procyanidin to the other and can greatly influence their overall 3D structure.

The 3D structures of synthesized procyanidin dimers [7] and trimers [8] in water were determined using both NMR and molecular modeling. The preferred $3 \mathrm{D}$ structures adopted in a wine-like medium are displayed in 0 Fig. $\mathbf{5}$. For dimers, the compact form always dominates, but in very different proportions from one dimer to the next (95\% for B1, 55\% for B2, 98\% for B3, and $76 \%$ for $\mathrm{B} 4)$. The heterocyclic rings (C/F) always adopt a conformation in which the catechol rings $(\mathrm{B} / \mathrm{E})$ are in the equatorial position. The 3D structure of trimers in a hydroalcoholic solution has also been reported previously for Cat-Cat-Cat and Cat-Cat-Epi 


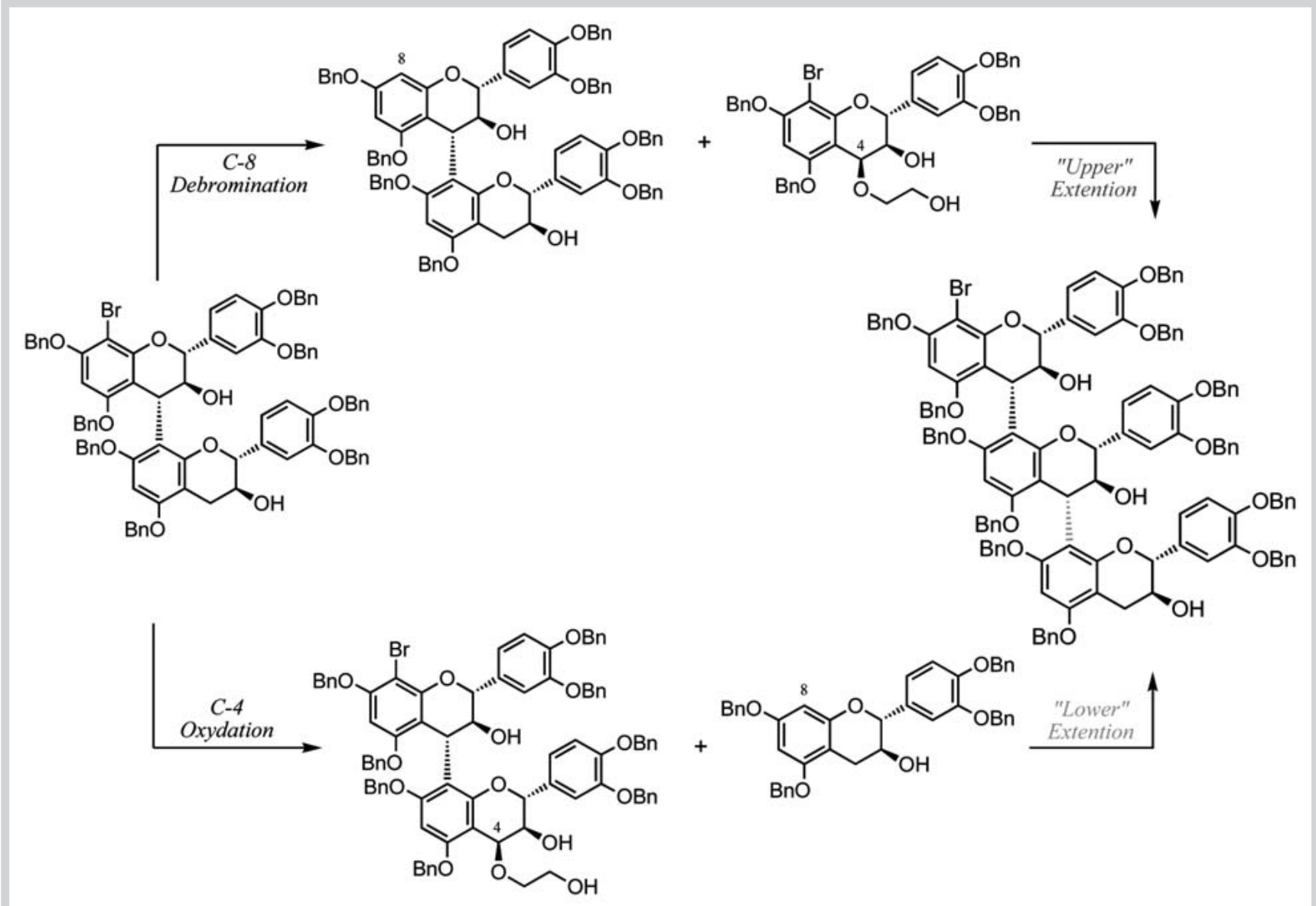

Fig. 4 Ways to access procyanidins with higher degrees of polymerization illustrated for trimers.
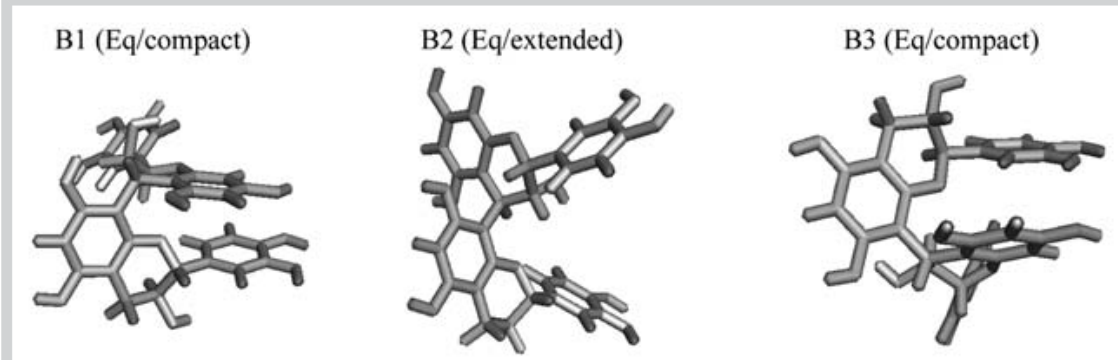

Fig. 5 3D structure preferences in a wine-like medium for the five different procyanidin dimers and one trimer.

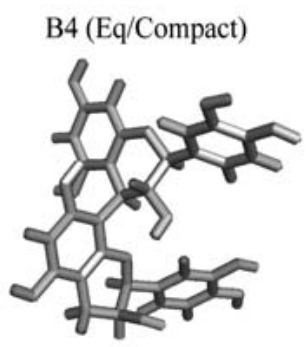

$\mathrm{C} 2$ (Eq-Eq-Ax/compact)

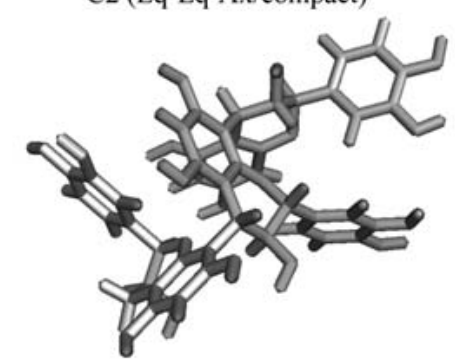

[8]. Four rotameric forms coexist, one of them being predominant. For the Cat-Cat-Cat trimer a compact-compact conformer predominates, in which the catechol rings $B$ and $E$ adopt an equatorial position when the $\mathrm{H}$ ring adopts an axial position $(60 \%$, ○ Fig. 5).
In light of these findings, it is clear that the complexity of the 3D structure of procyanidins increases with their degree of polymerization and that these molecules have to be considered as dynamic mixtures. 
The self-association that occurs when procyanidins are dispersed in water or hydroalcoholic solutions has to be investigated in order to evaluate their bioavailability towards saliva proteins, their real contribution in wine turbidity, and their probable influence for tannins/proteins interactions. This can be followed by measuring diffusion coefficient with diffusion NMR spectroscopy (DOSY) [9]. Under certain conditions, the diffusion coefficient of a molecular species depends on its molecular weight, size, and shape [20], but it can also be used as a probe to follow molecular association leading to varied "colloidal mixtures" $[13,21,22]$.

First, measurement of diffusion coefficient values at different tannin concentrations provides access to the association constant. The simplest way to characterize tannin self-association is to consider that all the stepwise association constants, Ka, are the same with respect to an isodesmic model [14]. In this case, Ka should be deduced from Eq. 1 by fitting the experimental data [9]. The values measured are close to $7 \mathrm{M}^{-1}$ for dimers and $5 \mathrm{M}^{-1}$ for trimers ( $\bullet$ Fig. $6 \mathrm{~A}$ ).

Second, the optimal conditions for micelle formation occur above the critical micelle concentration (CMC). This value is obtained by plotting the $D$ value against the inverse of the tannin concentration. As shown in $\odot$ Fig. 6B, two straight lines are obtained: one representative of the free state and the other of the aggregated state. The intersection of the two lines gives the inverse of the $\mathrm{CMC}$ value. It appears that the CMC value increases when the degree of polymerization of the tannin increases: from $\sim 10 \mathrm{~g} / \mathrm{L}$ for dimers to $13 \mathrm{~g} / \mathrm{L}$ for the trimer $\mathrm{C} 2$. Above this $\mathrm{CMC}$ value, micelles of polydisperse size are formed. The average size could be estimated from both the measurement of $D_{\text {micelle }}$ deduced from Equation 1 and $\odot$ Fig. 6B, and the following Stokes-Einstein relationship:

$\mathrm{D}=\mathrm{k}_{\mathrm{B}} \mathrm{T} / 6 \pi \eta \mathrm{r}_{\mathrm{H}}$

$\mathrm{R}_{\mathrm{H}}$ is the hydrodynamic radius of the formed micelle. While Ka and CMC values are of key importance to determine the "active" proportion of tannin able to fix proteins, $\mathrm{D}_{\text {micelle }}$ gives access to the mean size of the formed micelles and, thus, to the contribution of tannins in wine turbidity. It is noteworthy that significant differences are observed depending on the solvent used, for example, $10 \%$ ethanol increases tannin solubility. Finally, it is of interest to highlight that the average size that tannins micelles can reach decreases in the presence of $10 \%$ ethanol. Such small micelles cannot play a role in wine turbidity (around 25/13 $\AA$ for dimers and 50/23 Å for trimers in water alone/with $10 \%$ ethanol). A study of tannin-saliva proteins interaction has been undertaken in light of both structural and dynamical data obtained for procyanidin dimers and trimers. In the first step, a representative saliva peptide was synthesized [11]: IB7-14, as shown in $\bullet$ Fig. 2. It represents a model containing the repetitive sequence found two to five times in almost all basic PRPs [23]. The interaction between different procyanidins (B1, B2, B3, B4, and C2) and the IB714 fragment was monitored by using both chemical shift variations of selected peptide protons ( Fig. $7 \mathrm{~A}$ ) and DOSY-NMR experiments. Plotting these variations as a function of tannin concentration shows that the process is saturable binding, in accordance with a specific binding. That conclusion can be confirmed using DOSY-NMR experiments: collecting D values at various tannin concentrations ( $\odot$ Fig. 7 B) clearly shows their progressive decrease. The data suggest that the molecular object formed diffuses more and more slowly, as expected if procyanidin binds the peptide. By fitting the experimental chemical shift or $\mathrm{D}$ data
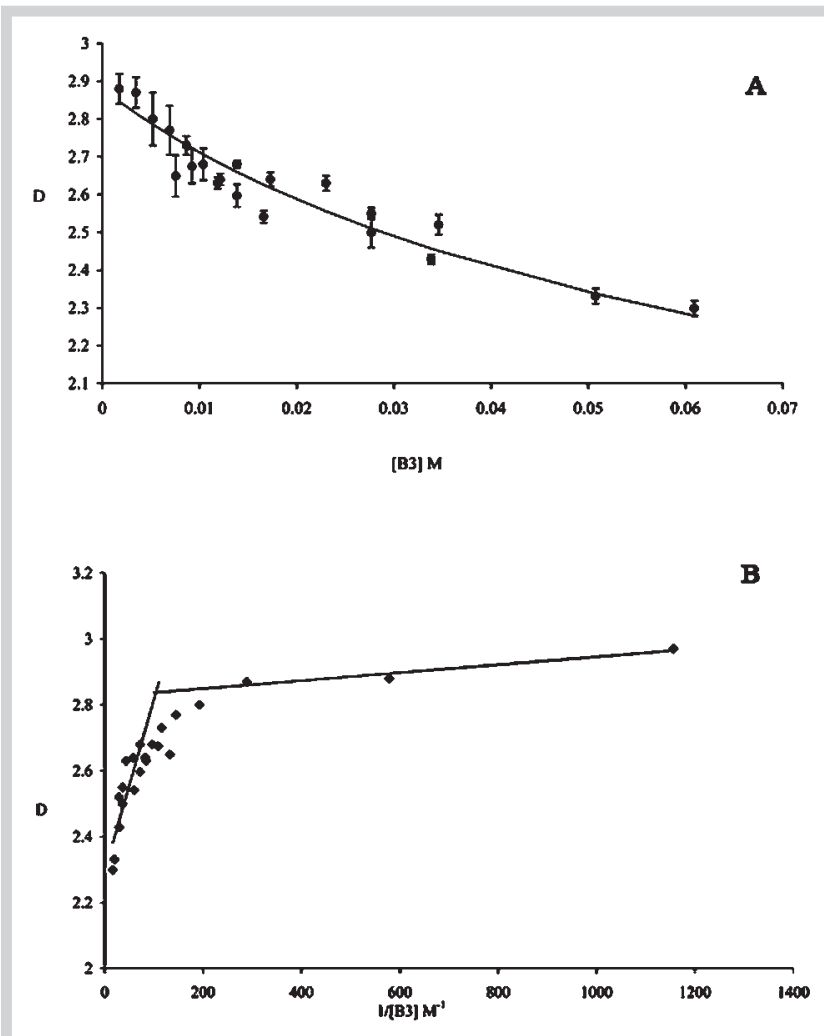

Fig. 6 Colloidal behavior of procyanidin B3. The two plots represent two ways of observing the evolution of $D$ with respect to tannin concentration. A A direct representation showing the decrease of $D$ that has been fitted using Eq. 1. Experimental points: symbol, calculated points: line. B An indirect representation showing the evolution of $D$ as a function of the inverse concentration of tannin. The intersection of the two lines gives the CMC value.

points using Eq. 2 and considering a multisite peptide-tannin interaction, where all the binding sites exhibit the same affinity [24], physicochemical parameters characterizing the complex formation were obtained ( $\odot$ Table 1). For all the tannins studied, the number of binding sites remains the same and is approximately three dimers or trimers for one peptide. These sites have been located at the level of the P2, P9-P10, and G13-G14 residues in the peptide [11] by using both ROESY experiments, chemical shift variations amplitude, and molecular dynamics (vide infra). However, great differences are observed between Kd values leading to an affinity scale in which C2 is 20 times more efficient in binding to the peptide than its dimer counterpart B3. These affinity differences can be correlated with structural preferences in solution as well as their ability to induce the peptide-tannin complex aggregation. The tannins that are most potent for inducing peptide precipitation are the dimer B2 and the trimer $\mathrm{C} 2$. These are also the procyanidins that appear to have structures in which the phenolic moieties are exposed so that one tannin can bind two peptides and initiate network formation and subsequent precipitation.

Molecular dynamic calculations were run in order to test whether the network initiation process could occur. In the first simulation, two peptides and three trimers were randomly dispersed in a full box of water to give a tannin concentration below their CMC ( $5 \mathrm{mM})$. At the end of the 60 ns calculation, one $\mathrm{C} 2$ was able to link two peptides ( Fig. 8A). The binding sites were the 


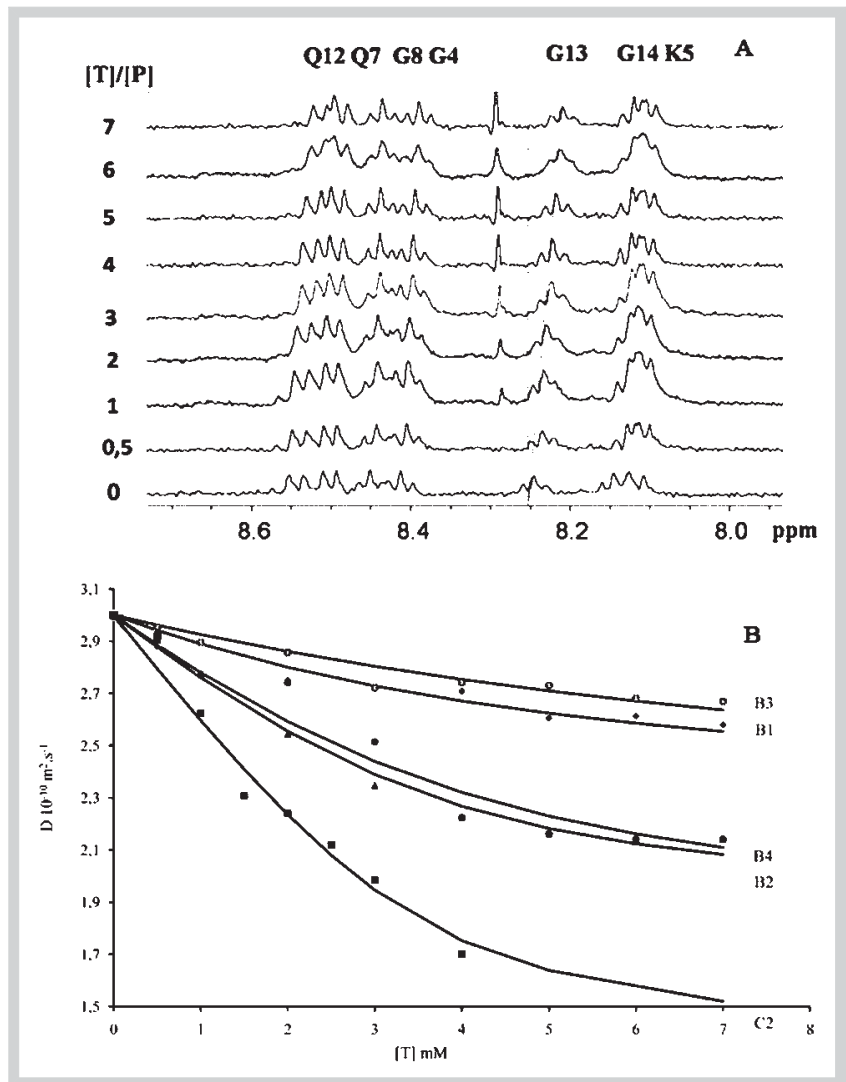

Fig. 7 Monitoring procyanidin-PRP interactions by using either chemical shift variation of the peptide $\mathrm{NH}$ resonances (A) or diffusion variation (B) as reported in $\odot$ Table 1.

same as those previously observed for B3 [11] and were located in the hydrophilic parts of the two peptides. The second run was performed with nine $\mathrm{C} 2$ trimers corresponding to a $15 \mathrm{mM}$ tannin concentration, i.e., at its CMC value. In the first few ns of this simulation, micelles of two to three $\mathrm{C} 2$ trimers are formed. The association between a peptide and a $\mathrm{C} 2$ micelle preceded formation of a more intricate supramolecule formed of at least six C2 trimers and two peptides ( $\mathbf{F i g . 8 B}$ ). In this particular case, random hydrophobic interactions and not specific stacking occur between tannin and protein.
Table 1 Binding, diffusion data, and sizes of soluble tannin-PRP complexes. Dissociation constants $\left(\mathrm{K}_{\mathrm{d}}\right)$ and number of tannin binding sites $(\mathrm{n})$ were obtained from the fit of experimental chemical shift variations of G13 and G14 $\mathrm{NH}, \mathrm{P} 2, \mathrm{P} 9$, and $\mathrm{P} 10 \mathrm{H} \alpha$ and from the diffusion coefficients variation for the peptides using Eq. 2. The different $K_{d}$ and $n$ values obtained for one tannin were averaged and are reported $\pm S D$. The hydrodynamic radius $R_{H}$ was obtained with the Stokes-Einstein Equation (Eq. 3).

\begin{tabular}{|c|c|c|c|c|}
\hline Procyanidins & $\mathrm{Kd}(\mathrm{mM})$ & n & $\begin{array}{l}D_{\max } \\
\left(10^{-10} \mathrm{~m}^{2} \cdot \mathrm{s}^{-1}\right)\end{array}$ & $\begin{array}{l}\mathbf{R}_{\mathbf{H}} \\
(\AA)\end{array}$ \\
\hline B1 & $2.9 \pm 1.4$ & $3.0 \pm 0.4$ & $2.2 \pm 0.1$ & $9 \pm 1$ \\
\hline B2 & $1.1 \pm 0.4$ & $3.2 \pm 0.5$ & $1.9 \pm 0.1$ & $11 \pm 1$ \\
\hline B3 & $8.0 \pm 0.9$ & $3.0 \pm 0.5$ & $2.1 \pm 0.1$ & $9 \pm 1$ \\
\hline B4 & $2.5 \pm 0.4$ & $3.5 \pm 0.3$ & $1.8 \pm 0.1$ & $11 \pm 1$ \\
\hline$C 2$ & $0.4 \pm 0.1$ & $3.0 \pm 0.2$ & $1.3 \pm 0.1$ & $15 \pm 1$ \\
\hline $\mathrm{IB} 7_{14}$ & & & $3.0 \pm 0.1$ & $7 \pm 1$ \\
\hline
\end{tabular}

All these results shed new light on the molecular explanation of tannin astringency. Two cases have to be taken into account depending on the colloidal state of tannins ( Fig.9). Below the CMC, tannins interact specifically with proline-rich peptides, with three specific binding locations. It was clearly established that the affinities of different tannins towards proline-rich peptides depend on their structural features: tannins presenting phenolic rings free of any intramolecular stacking are able to bind up to two PRPs with high affinity and initiate precipitation of the complex. Tannins that adopt a compact conformation bind only one peptide with a lower affinity. Above the CMC, tannins interact with PRPs in a micellar state: even if the first PRP appears to bind in a specific way (the same peptide sites are occupied initially as at lower tannin concentration), a more complicated complex is formed in fine in which both hydrophobic and hydrophilic forces are involved.

\section{Acknowledgements}

$\nabla$

We thank the Conseil Interprofessionnel des Vins de Bordeaux (CIVB), the Centre National de la Recherche Scientifique (CNRS), the Aquitaine Government, and the Université de Bordeaux for financial support, Nathan Mc Clenaghan for the review of the English language, and Paul de Boissel for the artwork.
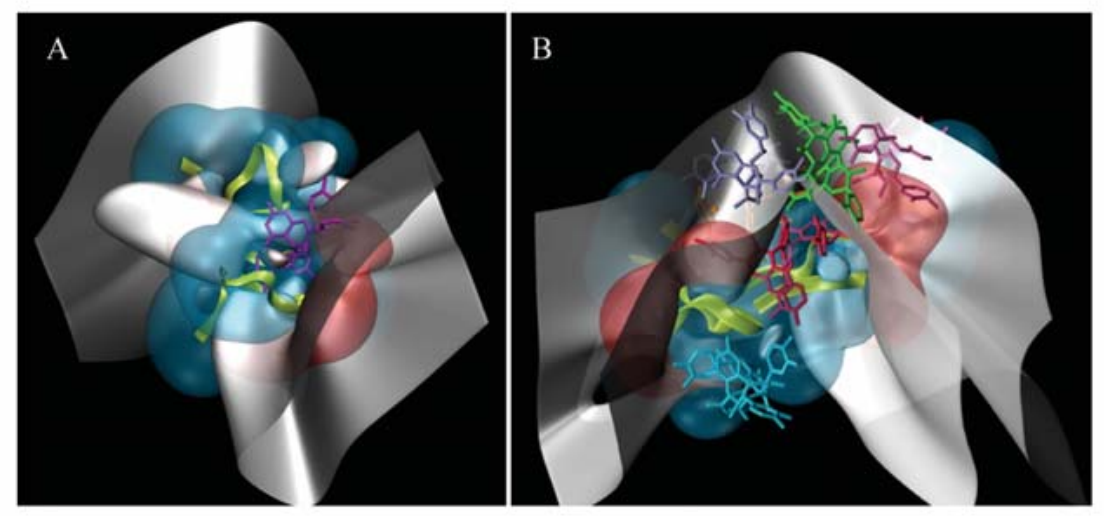

Fig. 8 Molecular lipophilic calculation of the complexes formed of 2 peptides (green ribbon) with 1 (A) or 6 C2 trimers (B). The hydrophilic part is shown in blue, the hydrophobic part in red and the interface in white. 


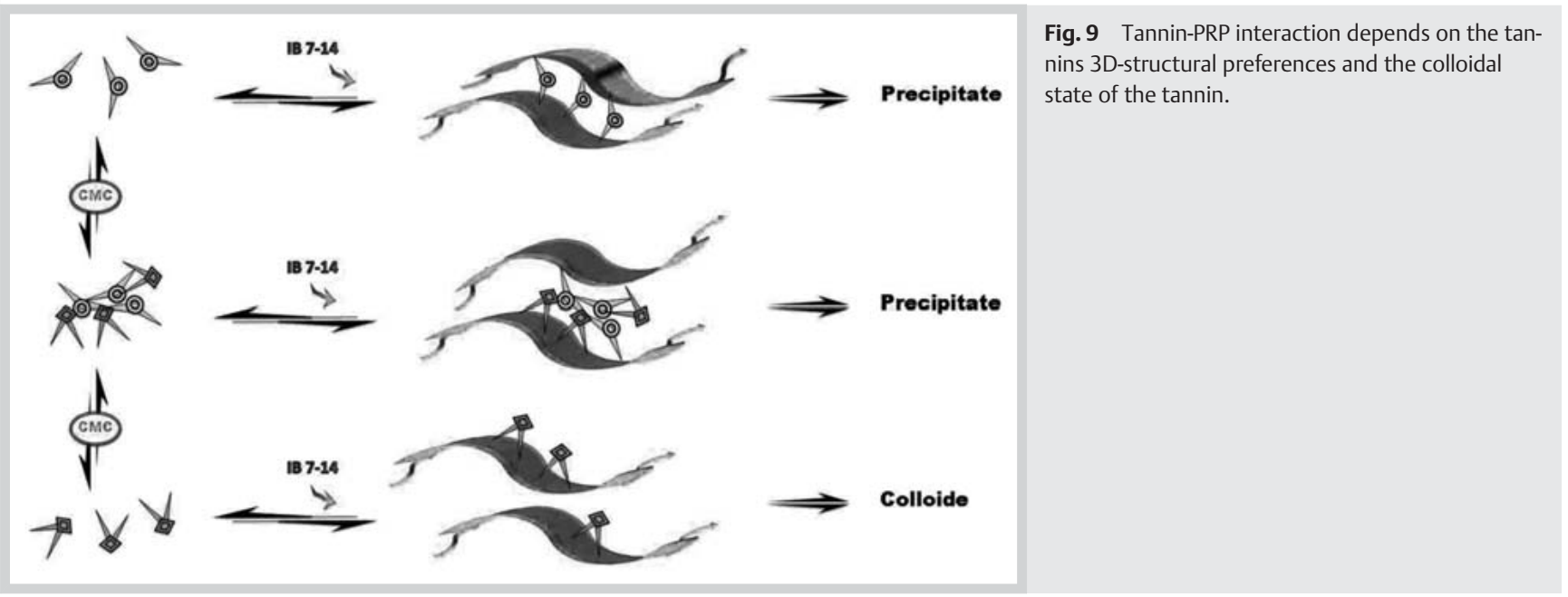

\section{References}

1 Joslyn MA, Goldstein JL. Astringency of fruit and fruit products in relation to phenolic content. Chichester: New York Academic Press; 1964

2 Bate-Smith EC. Astringency in foods. Foods 1954; 23: 124-134

3 Gawel R, Iland PG, Francis IL. Characterizing the astringency of red wine: a case study. Food Qual Prefer 2001; 12: 83-94

4 Bate-Smith EC, Swain T. Flavonoid compounds. In: Florkin M, Mason HS, editors. Comparative biochemistry, Vol. 3. New York: Academic Press; 1962: 75-809

5 Ribéreau-Gayon P. Plant phenolics. Edinburgh: Oliver and Boyd; 1972

6 Tarascou I, Barathieu K, Andre Y, Pianet I, Dufourc EJ, Fouquet E. An improved synthesis of procyanidin dimers: Regio- and stereocontrol of the interflavan bond. Eur J Org Chem 2006; 23: 5367-5377

7 Tarascou I, Barathieu K, Simon C, Ducasse MA, Andre Y, Fouquet E, Dufourc EJ, de Freitas V, Laguerre M, Pianet I. A 3D structural and conformational study of procyanidin dimers in water and hydro-alcoholic media as viewed by NMR and molecular modeling. Magn Reson Chem 2006; 44: 868-880

8 Tarascou I, Ducasse MA, Dufourc EJ, Moskau D, Fouquet E, Laguerre M, Pianet I. Structural and conformational analysis of two procyanidin trimers. Magn Reson Chem 2007; 45: 157-166

9 Pianet I, Andre Y, Ducasse MA, Tarascou I, Lartigue JC, Pinaud N, Fouquet E, Dufourc EJ, Laguerre M. Modeling procyanidin self-association processes and understanding their micellar organization: a study by diffusion NMR and molecular mechanics. Langmuir 2008; 24: 1102711035

10 Hagerman AE, Butler LG. The specificity of proanthocyanidin-protein interactions. J Biol Chem 1981; 256: 4494-4497

11 Cala O, Pinaud N, Simon C, Fouquet E, Laguerre M, Dufourc EJ, Pianet I. NMR and Molecular Modeling of wine tannins binding to saliva proteins: revisiting astringency from molecular and colloidal prospect. FASEB J 2010; 24: 4281-4290

12 Simon C, Pianet I, Dufourc EJ. Synthesis and circular dichroism study of the human salivary proline-rich protein IB7. J Pept Sci 2003; 9: 125131

13 Carteau D, Pianet I, Brunerie P, Guillemat B, Bassani DM. Probing the initial events in the spontaneous emulsification of trans-anethole using dynamic NMR spectroscopy. Langmuir 2007; 23: 3561-3565
14 Baxter NJ, Williamson MP, Lilley TH, Haslam E. Stacking interactions between caffeine and methyl gallate. J Chem Soc Faraday Trans 1996; 92: 231-234

15 Charlton AJ, Baxter NJ, Lilley TH, Haslam E, McDonald CJ, Williamson MP. Tannin interactions with a full-length human salivary proline-rich protein display a stronger affinity than with single proline-rich repeats. FEBS Lett 1996; 382: 289-292

16 Tückmantel W, Kozikowski AP, Romancsyk LJ. Studies in polyphenol chemistry and bioactivity. 1. Preparation of building blocks from $(+)$-catechin. Procyanidin formation. Synthesis of the cancer cell growth inhibitor, 3-O-galloyl-(2R,3R)-epicatechin-4,8-[3-O-galloyl(2R,3R)-epicatechin]. J Am Chem Soc 1999; 121: 12 073-12081

17 Saito A, Tanaka A, Nakajima N, Ubukata M. Efficient stereoselective synthesis of proanthocyanidin trimers with TMSOTf-catalyzed intermolecular condensation. SynLett 2004; 1069-1073

18 Steynberg JP, Brandt EV, Ferreira D, Helfer CA, Mattice WL, Gornik D, Hemingway RW. Conformations of procyanidins. In: Press P, editor. Plant polyphenols. New York: R.W. Hemingway and P.E. Laks; 1992

19 Hatano T, Hemingway RW. Conformational isomerism of phenolic procyanidins: preferred conformations in organic solvents and water. J Chem Soc [Perkin II] 1997: 1035-1043

20 Price WS. Pulsed-Field gradient nuclear magnetic resonance as a tool for studying translational diffusion: Part 1. Basic theory. Concepts Magn Reson 1997; 9: 299-336

21 Boisselier E, Ornelas C, Pianet I, Aranzaes JR, Astruc D. Four generations of water soluble dendrimers with 9 to 243 benzoate T ethers: synthesis and dendritic effects on their ion paring with acetyl choline, benzyltriethylammonium and dopamine in water. Chem Eur J 2008; 14: 5577-5587

22 Duluard S, Grondin J, Bruneel JL, Pianet I, Grelard A, Campet G, Delville $M H$, Lassegues JC. Lithium solvation and diffusion in the 1-butyl-3methylimidazolium bis(trifluoromethanesulfonyl)imid ionic liquid. J Raman Spectrosc 2008; 39: 627-632

23 Bennick A. Structural and genetic aspects of proline-rich proteins. J Dental Res 1987; 66: 457-461

24 Charlton AJ, Baxter NJ, Khan ML, Moir AJG, Haslam E, Davies AP, Williamson MP. Polyphenol/peptide binding precipitation. J Agric Food Chem 2002; 50: 1593-1601 